\title{
GUIDELINES FOT UPGRADING QUALITY OF LIFE IN LOW INCOME AREAS: A CASE STUDY - SABRA-TARIK JDIDEH, BEIRUT, LEBANON
}

\author{
MAGED YOUSSEF \& NOUR EL BABA \\ Faculty of Architecture - Design and Built Environment, Beirut Arab University, Lebanon
}

\begin{abstract}
Rapid urbanization, one of the greatest socio-economic changes during the last few decades, has caused the burgeoning of new kind of slums, the growth of squatter and informal settlements all around the rapidly expanding cities of the developing world. Urban populations have increased explosively in the past fifty years and this has continued gradually. Governments' neglect to the lowincome areas has generated the worst representations of urban poverty and inequality, having the highest concentration of poor people and the worst living conditions. This paper sheds the light on the problem of the existing complications in low-income areas on the social, educational, economic, cultural and environmental era which are experiencing a massive change in the quality of life for the low-income people. Ignorance of such glitches led the community to collapse, while people have their fundamental rights to live with basic dignity and in decent conditions. This paper, therefore, aims to produce guidelines for upgrading quality of life in low income areas. The Lebanese capital, Beirut, is one of the cities in the Middle East that has many deteriorated low-income areas due to several reasons. As a scoped case study, the paper analyzes the low-income area; Sabra-Tarik Jdideh, Beirut, which is mostly inhabited by refugees, homeless children, and fragmented families. In order to survey the current situation of Sabra's inhabitants, the paper follows a field methodology using interviews and a questionnaire. This methodology investigated the complications of low-income Sabra inhabitants and concluded with guidelines to upgrade the quality of life for them. These guidelines can be generalized on all low-income areas taking into consideration the special circumstances for every area. Consequently, upgrading the quality of life in low income areas can guarantee improving the educational, cultural, economic, environmental and social concerns of low income inhabitants. Keywords: architecture, quality of life, upgrading, low income areas, guidelines.
\end{abstract}

\section{INTRODUCTION}

Rapid urbanization, one of the greatest socio-economic changes during the last five decades or so, has caused the burgeoning of new kind of slums, the growth of squatter and informal settlements all around the rapidly expanding cities of the developing world. Urban populations have increased explosively in the past fifty years and will continue gradually. Low income areas represent the worst of urban poverty and inequality; they have the highest concentration of poor people and the worst living conditions [1]. Low-income society is largely made up of people earning their living on the informal sector of the economy; they have unsatisfied demand for financial services. Refugees are considered low income inhabitants. Refugees; this vulnerable population, have always occupied the lowest level of the social pyramid, not accessing most public services and not even being legally recognized as such. It is patently obvious that the life of the refugee is subject to a number of stressors, some of which are absent in the lives of the indigenous population [2]. Neighborhoods with poor-quality housing, few resources, and inadequate conditions are considered as a low-income area. As a result of the high cost of housing, the increasing 
population is forced to live in substandard housing and unhealthy conditions giving rise to poor residential neighborhoods. Low-income areas are increasing and posing serious problems to their own personal life and many other complications. Low-income inhabitants are experiencing a massive change in the quality of life as they remain in the settlements that are characterized by numerous problems such as lack of basic services especially water and sanitation, overpopulation, inadequate basic amenities, non-conventional housing, starvation, homeless populaces, sewage, socio-economic glitches, and weak infrastructure. Low income areas have high concentration of poverty and of social and economic deprivation which may include broken families, unemployment, and economic, social and physical exclusion and many other complications [1]. Quality of life is a term that has emerged as a concept of living conditions, health and physical safety, mental and social ability. Its definition can be categorized into several philosophical approaches. The first approach describes characteristics of the quality life that are dictated by normative ideals based on philosophy, belief and other systems. This approach depends neither on the subjective experience of people nor on the fulfillment of their wishes [3]. The second approach is based on satisfaction of preferences. Thus, the definition is based on whether citizens of a society can obtain things they need. While quality of life may mean different things to all these people, it typically encompasses a sense of socioeconomic security alongside the fulfillment of other non-material needs and aspirations. For a long time, prosperity was associated with income or wealth. But today, quality of life is considered to be one of the most significant aspects of prosperity [4]. Upgrading quality of life implies an improvement in living standards which tend to be measured by a variety of economic and social indicators and are therefore more related to consumption and income levels [5]. Poverty as a material concept is that people are poor because they lack the resources to get the things they need. The first set of definitions understands poverty as a lack of material goods or services [6]. Thus, upgrading quality of life in low-income areas requires significant guidelines to improve lives of low income inhabitants. This research explores both negative and positive aspects of low income areas. On the positive side, low-income areas - slum areas - are the first stopping point of immigrants - they provide the low-cost and only affordable housing. In addition, these areas are places that include vibrant mixing of different cultures. Unexpectedly, environments of these areas can generate cultural movements and levels of solidarity unknown in the suburbs of the rich. Against all odds, low income inhabitants have developed economically rational and innovative shelter solutions for themselves. However, these few positive attributes do not justify the continued existence of low income areas and should not be an excuse for the slow progress towards the goal of adequate shelter and proper living conditions for all [1].

The main aim of this research, therefore, is to produce detailed guidelines for upgrading quality of life in low income areas. To accomplish this aim, the research achieves the following goals: To create basic knowledge about low income people and their current situation in low income areas; to introduce countries' strategies about measuring and improving quality of life in low income areas; to explore both negative and positive aspects of these areas; to examine participatory slum upgrading programs that include urban poverty reduction objectives; to improve the living conditions of low income dwellers; and to reach a checklist to improve the quality of life in low income areas. The research hypothesis: Upgrading the quality of life in low income areas can improve the educational, cultural, economic, environmental and social concerns of low income inhabitants. The paper starts by introducing a literature review to recognize the previous studies and trials in upgrading the low-income areas internationally, and then it focuses on a case study of a low-income area in Beirut, Lebanon, titled (Sabra-Tarik Jdideh). 


\section{LITERATURE REVIEW}

For the literature review, initially the research concentrates on selected references that employ a qualitative methodology and which relate to low income areas upgrading with a focus on the guidelines in improving the living conditions.

One of the significant examples is an informal upgrading in Medellin, Colombia titled 'Library Parks, A Space to Join Together, in freedom and in dignity', as shown in Fig. 1. In 2007, Medellin began one of the most influential upgrading projects, a city-wide operation to provide informal settlements with sites and services that sought to integrate informal areas into the formal city. Medellin, for example, made a shift in focus from housing solutions to essential neighborhood infrastructure: transportation, education and public space. Library-Park, architect Giancarlo Mazzanti's dramatic design which, set as it is in one of Medellin's poorest areas, aims to symbolize the city's new image as a metropolis of culture, not crime. The library that overlooks the city not only became a new symbol for Medellin, but its plaza provided a leisure space that reinvented the alien nature of this new program inside the neighborhood [7]. This project aims to raise living standards through a series of new sustainable public spaces and social intervention. Like many areas of Colombia, violence, insecurity, and drug trafficking cause the area problems. Safe public spaces were needed to facilitate social exchange and prevent violence. By improving and building new public spaces, social development can occur to offset poverty [8]. Since the area is considered with greater educational, cultural, public spaces and basic services deficits, the library is placed either adjacent to them or in the interior of the informal urban fabric. The architect added and improved the public spaces in the area. He strengthened the low-income area as a new centrality with the implementation of education, cultural and sports programs and amenities [9]. The rock-inspired design meant to mimic the geographical landscape. In addition to the library, there are also a community center and cultural center in the park [8].

The architect stated that he wanted to take people from this poor community into another world and change their reality [9]. The educational opportunities are symbols of renewed social change and provide a precedent for other cities [10].

Another example of informal upgrading is in Caracas, Venezuela, Vertical Gymnasium "Opportunities for the community", as shown in Fig. 2. The upgrading process included a project that transformed an eroded landscape into a productive zone and dynamic public space. The project, led by architects Brillembourg and Klumpner, includes a terraced public space with areas for urban agriculture, a water management system, a public amphitheater, a music school, a small concert hall, sports facilities, public spaces and transport infrastructure. This is distinguished by its unifying concept, premium cultural and social facilities, architectural quality, and integrated involvement of the local community in a
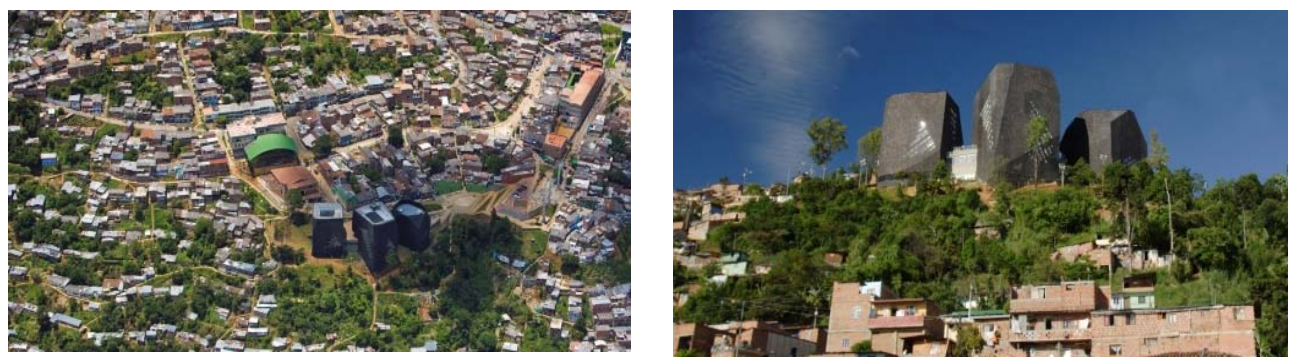

Figure 1: (a) On the left - Aerial View of Bibliotheca España, Medellin, Colombia; (b) On the right - Perspective View of Biblioteca España, Medellin, Colombia. 


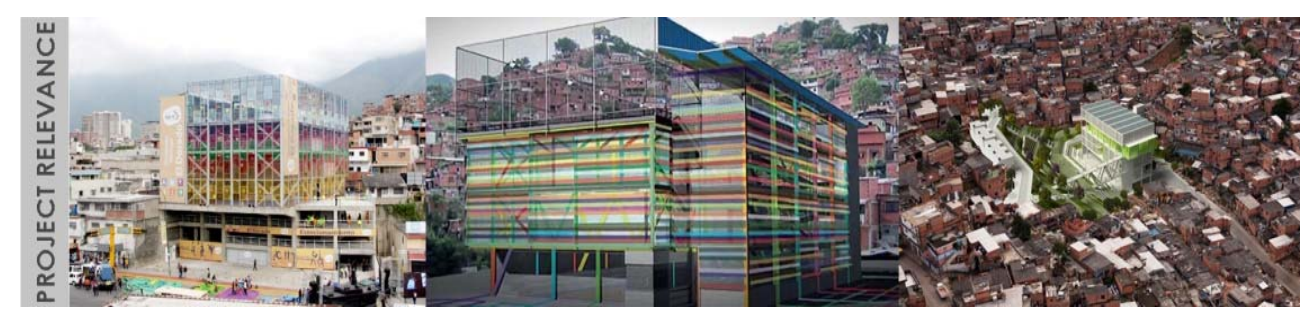

Figure 2: Projects relevancies; regarding the vertical gymnasium in Caracas, Venezuela.

socially-inclusive planning and management approach. This important intervention has the capacity to provide satisfaction and opportunities for the local community that creates both connectivity and the construction in a viable way [11].

After presenting a literature review recognizing two examples tried to upgrade low income areas, the paper will analyze a case study in Lebanon following a specific methodology.

\section{METHODOLOGY}

The paper examines a case study to deduct guidelines for upgrading quality of life in the low-income area Sabra-Tarik Jdideh, Beirut Lebanon. It applies four research methods; First, the inductive method gathering data about the selected area. Second, the field method, the authors visited the site, taking live photographs, undertaking interviews with inhabitants recognizing their opinions of the existing problems. In addition, the authors designed a questionnaire form and distributed it on a sample of inhabitants to obtain tangible results. Third, the analytical method, the paper analyzes results of interviews and the questionnaire. Fourth, the deductive method, as a final step, the paper deducts a checklist as a guideline for upgrading quality of life in low income areas. These research methods will be represented through the following points.

\subsection{Introducing the case study, "Sabra-Tarik Jdideh, Beirut, Lebanon"}

After the Lebanese Civil War in 2006, Beirut has become opened to the international development market. Despite all merits of Beirut, rapid urbanization has led to expansion of informal settlements including refugee camps where low-income areas have secured informal shelter and where quality of life is often markedly below standards including poverty, inequality, child labor, unemployment, educational crisis, and social deprivation [12]. Tarik Jdideh in Beirut is a low-income area due to the existing complications concerning the quality of life. At the intersection of northern and southern Beirut rises Sabra and Shatila refugee camp as shown in Fig. 3. The camp was set-up for Palestinian refugees in 1949. Tarik El Jdideh is extending from 'Horch Area' from the north until the last Sabra Street to the south [13].

\subsection{Historical background of "Sabra-Tarik Jdideh"}

Thirty-three years ago, a massacre that shocked the world unfolded in Beirut's Palestinian refugee camps of Sabra and Shatila, as shown in Fig. 4. More than 1500 Palestinian civilians were killed by Israeli-allied Christian militiamen during Israel's 1982 invasion of Lebanon. For Palestinians, this massacre was and remains a traumatic event, commemorated annually. Survivors continue living there struggling to eke out a living and haunted by their memories of the slaughter [14]. 

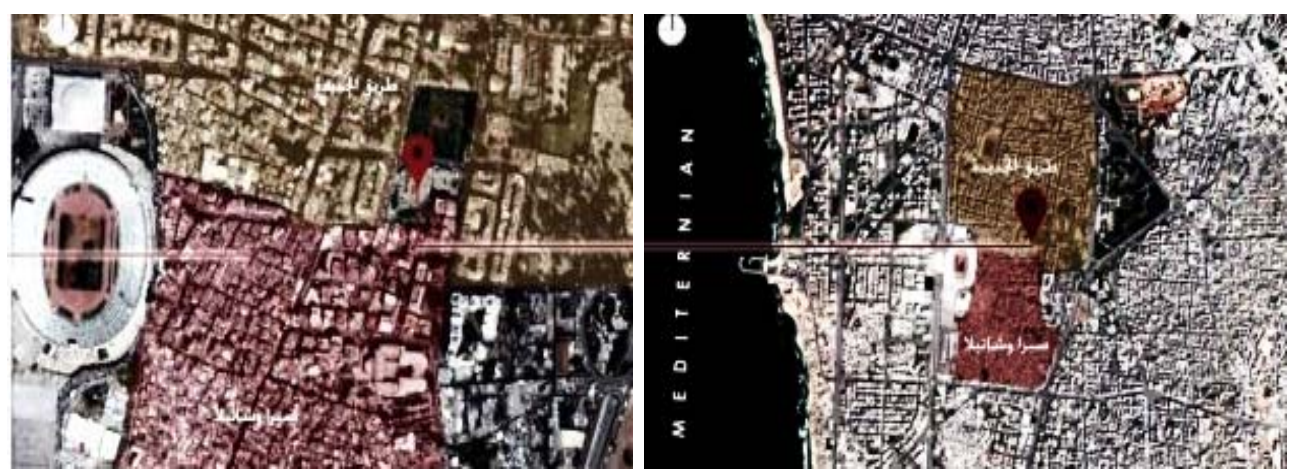

Figure 3: Two maps showing the location of Sabra-Tarik Jdideh, Beirut, Lebanon.
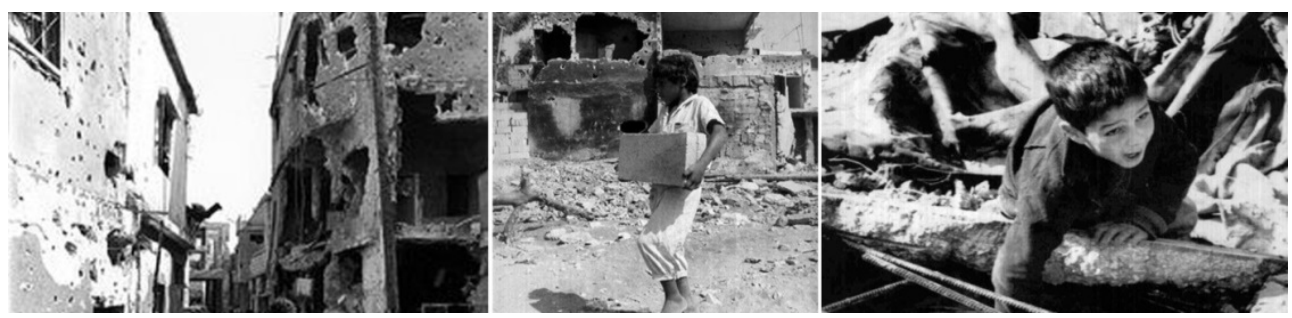

Figure 4: Pictures of the Massacre that happened in Sabra and Shatila Camp in 1982.

\subsection{Population of "Sabra-Tarik Jdideh"}

In this area, the population houses more than 9842 registered Palestine refugees [15]. Since eruption of the Syrian civil war, the camp has enlarged with Syrian refugees. Population there today comprises more than a quarter million people that is equivalent of more than a quarter of the population of Beirut [15].

\subsection{Problems of "Sabra-Tarik Jdideh"}

The diagram, shown in Fig. 5, represents the existing problems of this area.

First - Child Labor: The Lebanese Labor Law defines a child as all individuals below the age of 18 [16]. Socioeconomic data from the target area are scarce, but the current status shades low education levels, low wages, and an elevated incidence of poverty. Target population consists of employed children in the informal labor market of Sabra and Tarik Jdideh, as shown in Fig. 6. Children between 8 and 18 years of age are targeted.

Second - Educational Crisis: Due to extreme poverty and instability of life in some cases of refugees, many families are unable to provide their kids with the needed education. This lack of education led to child labor. Ignorance of such glitches causes the community to collapse. Third - Social Deprivation: Lacking gathering places, safe public spaces were needed to facilitate social exchange and prevent violence. Often the minimum requirements for living are missing such as intermingling with the neighboring societies. Fourth Cultural Spreading Deficiency: From the crowded and dangerous environments, cultural movements can emerge. One of the significant cultural craft of Palestinians is "Tatreez", the embroidery craft, which is missing in the area. Fifth - Scattered Economic Platforms: Platforms with the existing pollution is a significant problem. In addition, the shading of the corresponding area is inappropriate and not well shaded as shown in Fig. 7. 


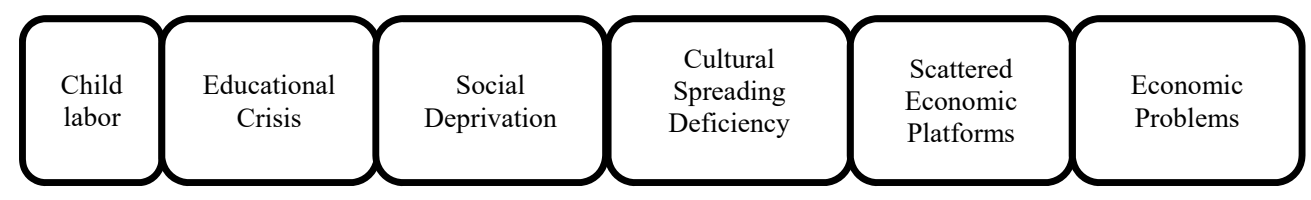

Figure 5: The most six noticeable problems existed in "Sabra-Tarik Jdideh."
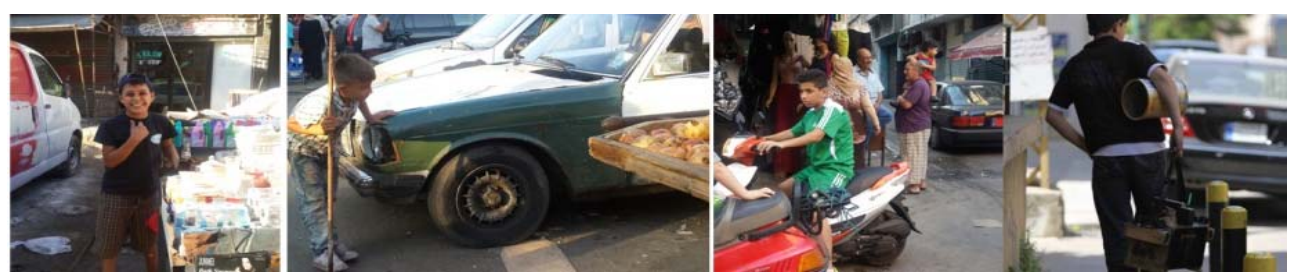

Figure 6: Pictures showing child labor in the local area Sabra-Tarik Jdideh.(Photographs taken by the authors, 12 November 2016.)

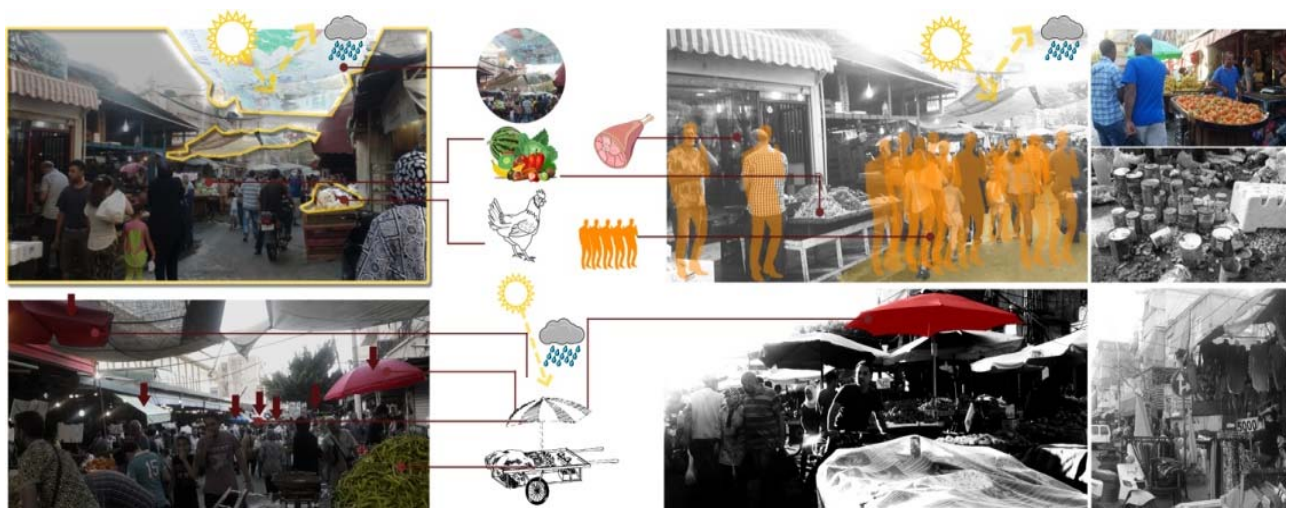

Figure 7: The existing scattered economic platforms in the low-income area. (Photographs and Analysis by the authors, 13 November 2016.)

Sixth - Economic Problem: Most of Lebanese syndicates do not give permission to the refugees to work, in which they are not allowed to own their own companies, and their only resource for work is to get a job under someone's name. Percentage of unemployment among refugees is obviously increasing as shown in Fig. 7.

\subsection{Site Selection in "Sabra-Tarik Jdideh"}

To focus the study, the authors selected one spot as a limited site. It is located at a central point between Sabra and Tarik Jdideh, shown in Fig. 9. The importance of this site is its location on a vital axis, "Ghobeiry Axis".

\subsection{Biological Attributes of "Sabra-Tarik Jdideh"}

The area contains a limited amount of green spaces; vegetation as shown in the Fig. 8. 

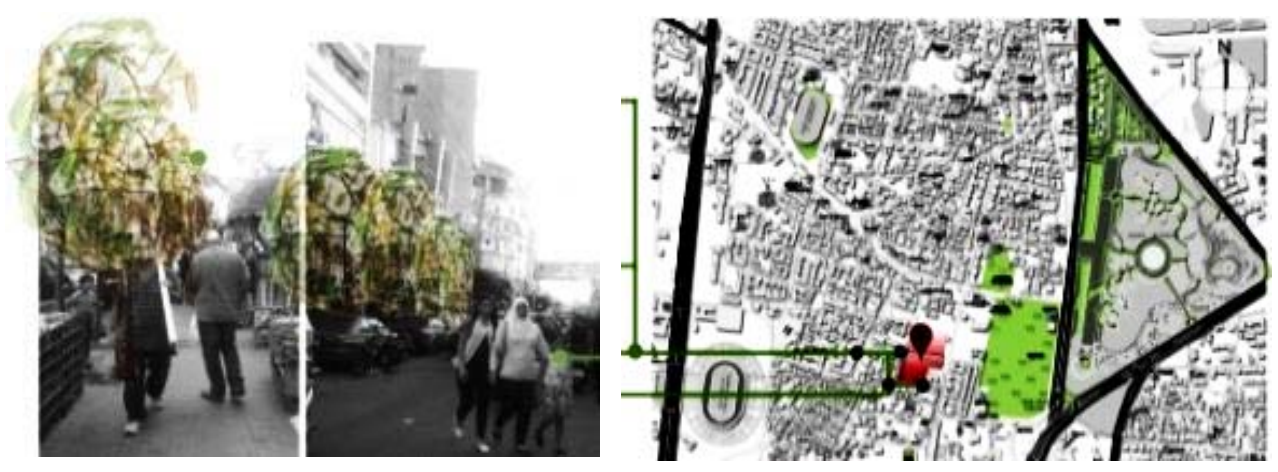

Figure 8: Photos and a map showing existing trees and green areas surrounding the site. (Photographs taken by the author, 13 November 2016 - Analysis by the authors.)

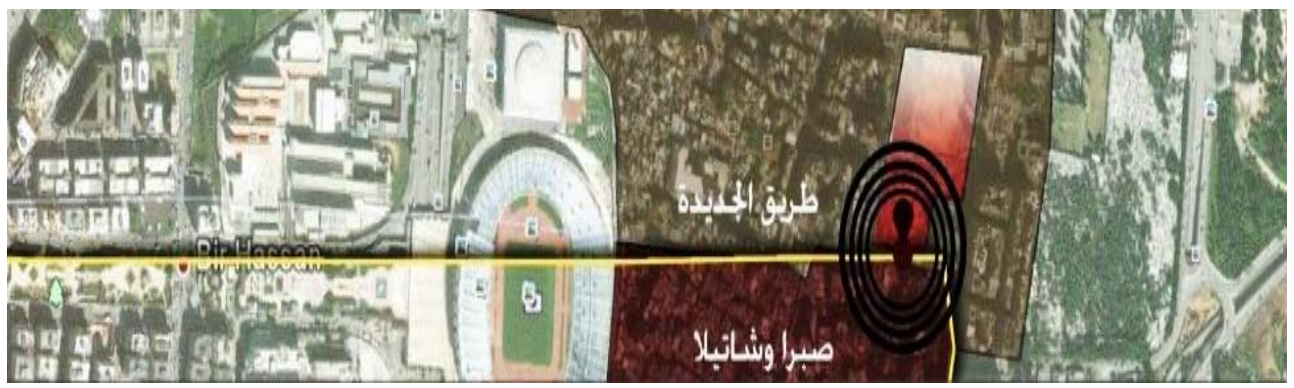

Figure 9: A map showing the chosen site in Sabra and Tarik Jdideh to be the focused study.

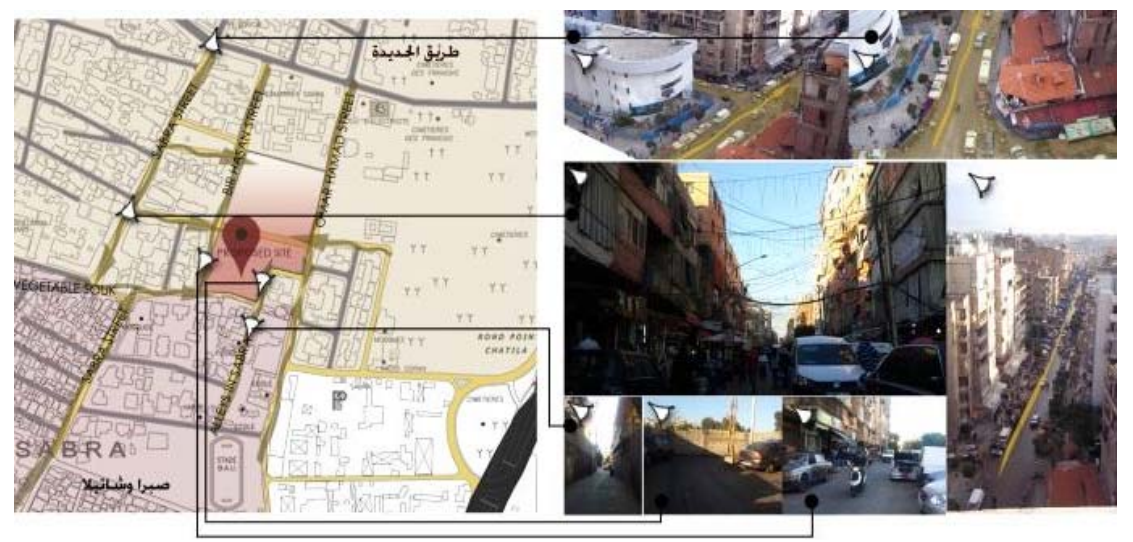

Figure 10: Map and photos showing the road network and site accessibility.

This site is surrounded by slums and residential buildings. It serves communities of Sabra and Tarik Jdide. Shifting the site to the borders can homogenize both communities and attract middle income people. 
3.7 Road network and accessibility to the chosen site

The proposed site is accessible from different arterials. The first access is from slum area Sabra Refugee Camp from the south, the second one is from the low-income area of Tarik Jdideh from the north and west. The third access is from the middle-income area from the east side of the proposed site as shown in Fig. 10.

\subsection{Building materials in the chosen site}

As shown in Fig. 11, building materials in Sabra include natural stone, paint, coatings and bricks with no finish and other materials indicating the bad conditions of buildings.

\subsection{Pedestrian flow and commercial activities of the chosen site}

The pedestrian flow is existed through an "internal barrier path" separating Sabra Refugee Camp and Tarik Jdideh. This path ensures a transition in the typology and skyline of buildings. Maps of Fig. 12 show this flow from the two regions into the proposed site and show the commercial wall activities around site with pictures of the inner streets in Sabra.

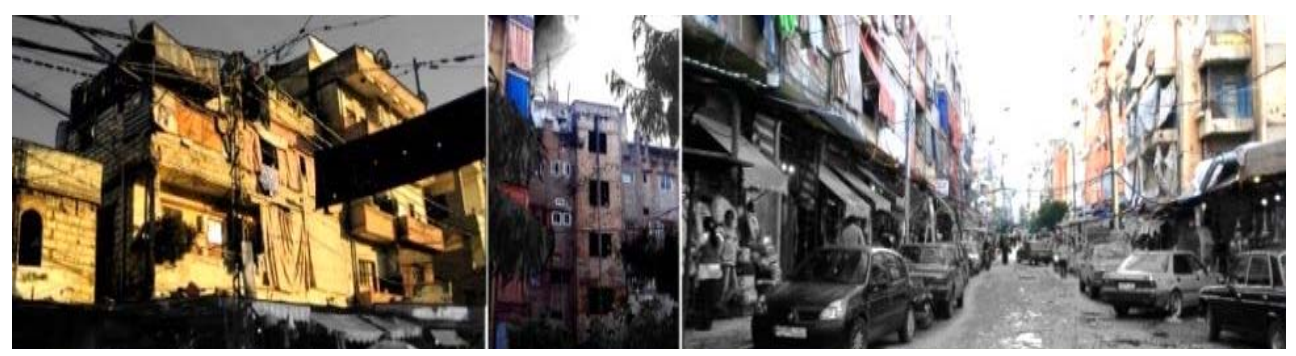

Figure 11: Building materials in Sabra-Tarik Jdideh. (Photographs taken by the authors, 17 November 2016).
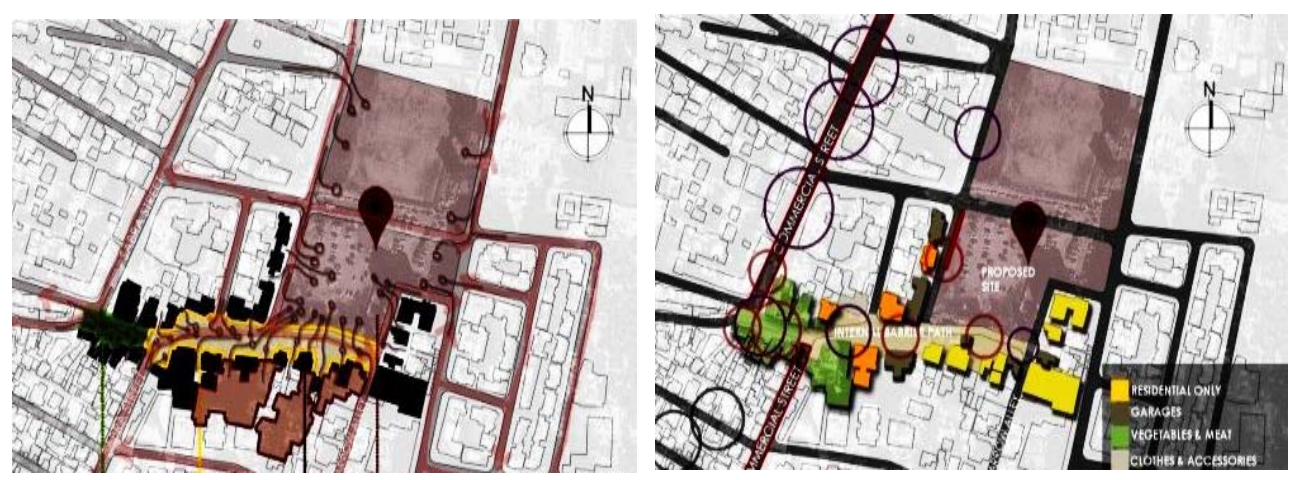

Figure 12: Maps showing the pedestrian, vehicular flow, and the commercial wall activities on ground floor and the noise and smell analysis around the site in Sabra-Tarik Jdideh. (Analysis by the authors.) 
After surveying the site by photographing buildings, streets, and the landscape elements, the researchers held meeting with a sample of site's inhabitants.

\subsection{Meetings with inhabitants from the chosen site}

In order to reach tangible findings, the authors preferred to meet samples of site's inhabitants to recognize their opinions, following two ways; interviews and a questionnaire.

\subsubsection{Interviews}

Face to face interviews were undertaken with teenagers because it is logically to upgrade a low-income area; firstly, you should shelter, educate, and employ its most interactive manpower, (teenagers), who can be employed in different facilities, so it was important to target this age group. Important interview questions include: What do you do every day from morning until evening? Do you attend school? What do you do together with your friends? Samples of answers were:

Ahmad, (14 years old):

In the morning I go and work, from eight o'clock to eight o'clock. I come home and take a shower, sometimes I go outside a little bit like, I walk around or I'll stay in my home.

Mostafa, (7 years old):

No, I don't go to school. My father died recently and I work at the garage to support my family, I don't know how to read and write.

Khaled, (11 years old):

I play with my friends in the neighborhood and smoke and I am close to my relatives, I mean it is not so nice outside and like that, we are on our own there. It is nice here we got used to it... Outside we will need another five years to get used to it.

Some children however are full-time workers at a very young age. Most children there drop out in middle school to find a job to help out their families. Ahmad is an example of somebody who dropped out of school, and dedicated his life to work. In addition, the area unfortunately lacks the outdoor facilities that can attract the children. These facilities such as the shopping malls, amusement parks, seaside where not found inside the region and are viewed as fun places to explore. Adults on the other hand had a different connection with the outside of the region whether for work purposes or for other services.

\subsubsection{Questionnaire}

The research used a closed questionnaire divided into six questions. The target group was random inhabitants, from 7 to 20 years old because they are affecting the upcoming generations. The questionnaire was filled by fifty persons to ensure several opinions and to figure out what facilities can assess quality of life. Five questions were directed to the sample: What are the significant problems in the area? What is your educational level? At what age did you drop out school? Why did you drop out school? and What facilities do you prefer to be provided to upgrade your community?

\section{FINDINGS}

The research follows an analytical methodology to analyze answers said in the interviews and answers mentioned in the questionnaire forms. 
Table 1: Table shows needs of inhabitants in Sabra-Tarik Jdideh.

\begin{tabular}{|c|c|c|c|c|c|}
\hline $\begin{array}{c}\text { Educational } \\
\text { environment }\end{array}$ & $\begin{array}{c}\text { Social and } \\
\text { cultural facilities }\end{array}$ & $\begin{array}{c}\text { Upgraded public } \\
\text { amenities }\end{array}$ & $\begin{array}{c}\text { Recreational } \\
\text { facilities }\end{array}$ & $\begin{array}{c}\text { Green } \\
\text { spaces }\end{array}$ & $\begin{array}{c}\text { Commercial and } \\
\text { retail facilities }\end{array}$ \\
\hline Library & Craft workshops & $\begin{array}{c}\text { Flexible } \\
\text { Community } \\
\text { Rooms }\end{array}$ & $\begin{array}{c}\text { Sports } \\
\text { facilities }\end{array}$ & $\begin{array}{c}\text { Park } \\
\text { features } \\
\text { Plaza }\end{array}$ & $\begin{array}{c}\text { Economic } \\
\text { Platforms }\end{array}$ \\
\hline
\end{tabular}

\subsection{Findings of the interviews; checklist of the needs in Sabra-Tarik Jdideh}

From answers of interviews, the research can deduct a checklist of needs that can effectively improve quality of life in the area. This checklist is represented in Table 1.

\subsection{Findings of the questionnaire}

As shown in the chart of Fig. 13 (a), poverty was the first problem that was mentioned by $28 \%$ of the sample, then pollution and sewage (referred by $25 \%$ ). Other problems were mentioned such as social deprivation and culture spreading deficiency. Concerning the educational level, $29 \%$ answered that their education stopped at the primary level, and unfortunately most of the sample dropped their education between the ages at 10 to 15 years, (34\%). According to answers, the reason why students dropped out school was due to domestic problems and most of the family's members have to work to spend money on living expense. This reason was said by $31 \%$ of the sample, which was the highest percentage. As shown in the chart of Fig. 13 (b), regarding inhabitants' opinions to provide facilities serving and upgrading the area, $18 \%$ of the sample emphasized the importance of providing the vocational training and the same percentage envisioned that offering social and cultural facilities may refresh the area healthy and useful activities.

\section{DISCUSSION}

The research proposes guidelines for upgrading quality of life in low income areas. The first guideline is to apply paintings on the existing walls of buildings of the internal barrier path that can transform the aesthetic and the social psychology of the whole area; turning public urban spaces and deprived places into inspiring artworks of monumental size, as Fig. 14. This guideline can be achieved through encouraging the teenagers and the youths to contribute in these wall-paintings.

The second guideline is to reuse the existing scattered wood in the low-income area and implement wooden perforated shelters on the internal barrier path by using a traditional Palestinian pattern used in Palestinian embroidery to recall area's culture, as Fig. 15. These shelters can be constructed by the Palestinian refugees who are living in the area, specially workers, carpenters, and blacksmiths. The third guideline is to supply community spaces and enhance services that equip the area with community centers, libraries, and social services, educational facilities including vocational classes, and other elements vital to the social life. The fourth guideline is to ensure green spaces and landscape architecture to upgrade the community and ensure a clean environment in the low-income area. To apply the last two guidelines, the Lebanese Government should intervene through three ministries; Ministry of Culture, Ministry of Education, and Ministry of Environment. 
What are the significant problems in the area?

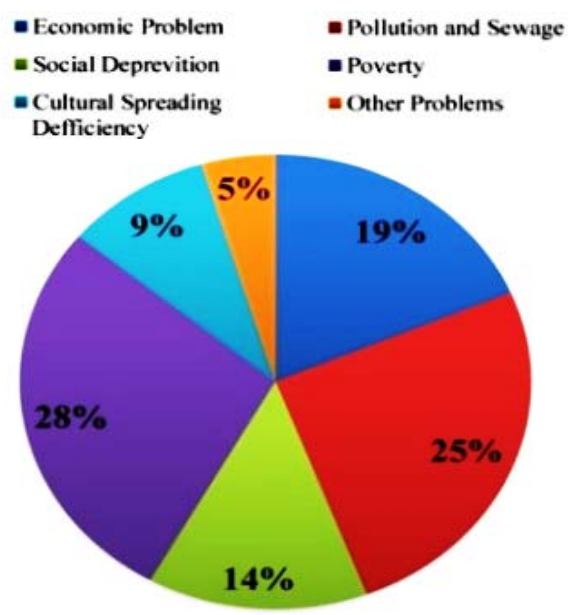

What facilities do you prefer to be provided to upgrade your community?

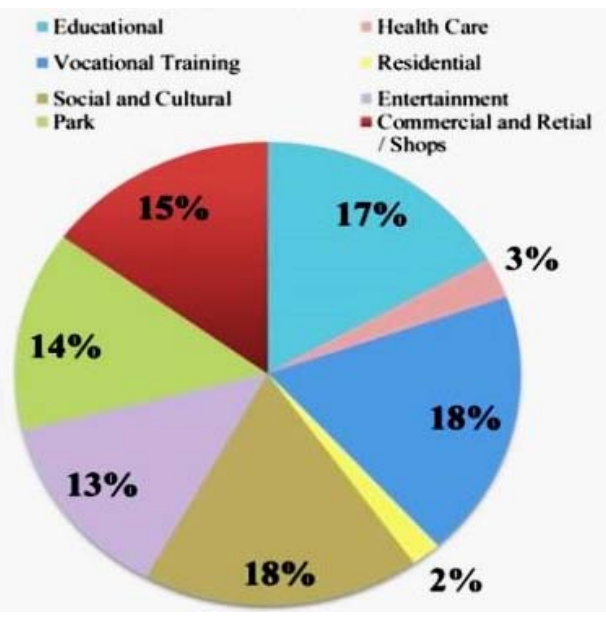

Figure 13: (a) On the left - Chart of answering the first question; (b) On the right - Chart of answering the last question

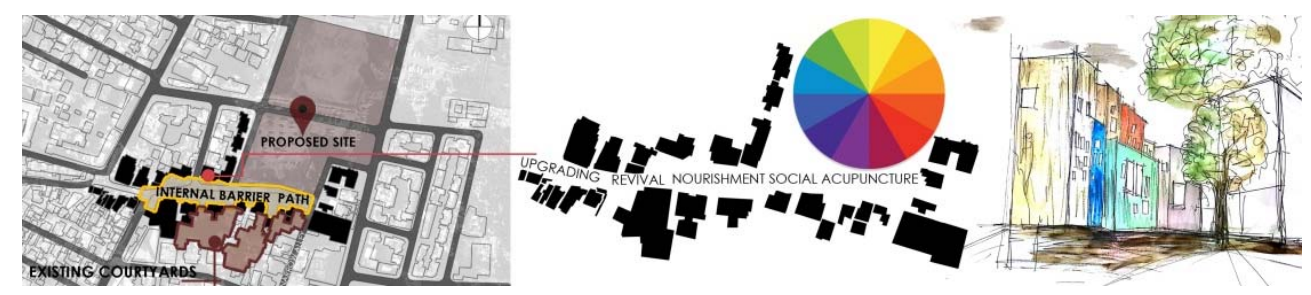

Figure 14: The first guideline concerning Paintings on walls of the low-income area.

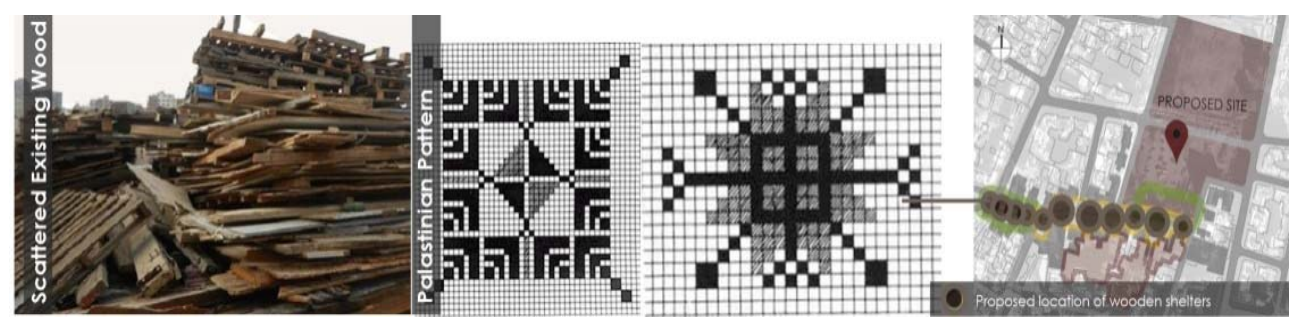

Figure 15: The second guideline concerning the wooden shelters of Palestinian pattern

\section{CONCLUSION}

This paper ends up with a set of conclusions as follows:

1. Upgrading quality of life in low income areas can guarantee improving the educational, cultural, economic, environmental and social concerns of low income inhabitants. 
2. By applying the mentioned guidelines, there is an increasing emphasis on the significance of low income area upgrading instruments as a sustainable approach to improve the life of dwellers.

3. This study found that, the upgrading process can be activated through supplying low income areas with facilities according the existing complications and the community's needs. Subsequently, satisfaction with the quality of life increases drastically by upgrading the low-income area.

4. This paper is considered as a scream to the decision makers of governments, United Nations, and Human Rights Organizations to give much concern to this layer of people who have great potential and yet have not been employed. Apply these guidelines.

\section{REFERENCES}

[1] United Nations Human Settlements Programme, The Challenge of Slums: Global Report on Human Settlements Programme, 1, Earthscan Publications, VA: London and Sterling, 2003.

[2] Capri, E., De-Homogenizing Poverty in the Southern Suburbs of Beirut: When Citizenship Disempowers, American Research Institute for Policy Development, 2015, Online. http://jswhr.com/journals/jswhr/Vol_3_No_1_June_2015/3.pdf. Accessed on: 1 Nov. 2016

[3] Amao, F.L., Quality of Life of Poor Residential Neighborhoods in Oshogbo, Nigeria, Waset.org.2014, Online. http://waset.org/publications/9997872/quality-of-life-ofpoor-residential-neighborhoods-in-oshogbo-nigeria. Accessed on: 1 Jan. 2017.

[4] Mboup, G., Urban quality of life - concepts and measurements, Developmentprogress.org., 2014, Online. http://www.developmentprogress.org/blog/ 2014/02/06/urban-quality-life-\%E2\%80\%93-concepts-and-measurements. Accessed on: 1 Nov. 2016.

[5] Jovanovic, M., 2 Improving the quality of life in rural areas, Leader.org.rs, Online. http://www.leader.org.rs/csd/en/Download/Information-Package/68-2. Accessed on: 1 Nov. 2016

[6] Spicker, P., Definitions of poverty: twelve clusters of meaning, 1999, Online. http://citeseerx.ist.psu.edu/viewdoc/download?doi=10.1.1.701.60\&rep=rep1\&type $=p$ df. Accessed on: 10 Dec. 2016.

[7] Chris, C., Safety in Colombia Week: The dramatically changing faces of Bogotá and Medellín, Colombia Travel Blog by See Colombia Travel, 2012, Online. http://seecolombia.travel/blog/2012/04/safety-in-colombia-week-the-dramaticallychanging-faces-of-bogota-and-medellin. Accessed on: 18 Nov. 2016.

[8] Mazzanti, G., Celsus: A Library Architecture Resource - Spain Library, Medellín, Colombia (building), Libraryarchitecture.wikispaces.com, 2016, Online. https://libraryarchitecture.wikispaces.com/Spain+Library, \%20+Medell\%C3\%ADn, \% 20+Colombia+(building). Accessed on: 18 Nov. 2016.

[9] "Parque Biblioteca España/Giancarlo Mazzanti" Plataforma Arquitectura, 2008, Online. http://www.plataformaarquitectura.cl/cl/02-6075/biblioteca-parque-espanagiancarlo-mazzanti. Accessed on: 1 Jan. 2017.

[10] Guttlab, S., case studies - informal settlements, Guttlab, 2012, Online. https:/guttlab.wordpress.com/guttlab-01-minnesota-usa/2-informal-settlementsanalysis/. Accessed on: 1 Jan. 2017. 
[11] Db, R., Urban Think Tank: grotão fábrica de música designboom architecture \& design magazine, 2012, Online. http://www.designboom.com/architecture/urbanthink-tank-grotao-fabrica-de-musica. Accessed on: 20 Nov. 2016.

[12] Ill-health linked to poor housing quality in a low income urban community on the outskirts of Beirut, Research and Policy Highlights, 2010, Online. https://www.aub.edu.lb/fhs/crph/publications/Documents/CRPH_research_brief3_en glish.pdf. Accessed on: 1 Jan. 2017.

[13] Macfarlane, J., Syrian refugees fear permanent exile in Lebanon's camps - BBC News, 2014, Online. http://www.bbc.com/news/world-middle-east-26816043. Accessed on: 20 Nov. 2016.

[14] Kadi, S., The Arab Weekly, Decades after Sabra and Shatila Massacre, Impunity still unchallenged, 2015, Online. http://www.thearabweekly.com/Interview/2226/ Decades-after-Sabra-and-Shatila-massacre $\% 2 \mathrm{C}$-impunity-still-unchallenged. Accessed on: 20 Nov. 2016.

[15] Mackenzie, L., Shatila's population unknown as Palestinian refugee camp bursts at seams, The National, 2016, Online. http://www.thenational.ae/world/middleeast/shatilas-population-unknown-as-palestinian-refugee-camp-bursts-at-seams. Accessed on: 1 Nov. 2016.

[16] WCH, Situation Assessment of Child Labor in Beirut's Southern Suburbs, War Child - Holland, 2012, Online. https://www.warchildholland.org/sites/default/ files/bijlagen/node_14/31-2013/child_labour.pdf . Accessed on: 1 Jan. 2017. 